\title{
Clathrin-Independent Pathways of Endocytosis
}

\author{
Satyajit Mayor ${ }^{1}$, Robert G. Parton ${ }^{2}$, and Julie G. Donaldson ${ }^{3}$ \\ ${ }^{1}$ National Centre for Biological Sciences, Tata Institute of Fundamental Research, and Institute for Stem \\ Cell Biology and Regenerative Medicine, Bangalore 560065, India \\ ${ }^{2}$ The University of Queensland, Institute for Molecular Bioscience and Centre for Microscopy and \\ Microanalysis, Queensland 4072, Brisbane, Australia \\ ${ }^{3}$ Cell Biology and Physiology Center, National Heart, Lung, and Blood Institute, National Institutes \\ of Health, Bethesda, Maryland 20892 \\ Correspondence: mayor@ncbs.res.in
}

There are many pathways of endocytosis at the cell surface that apparently operate at the same time. With the advent of new molecular genetic and imaging tools, an understanding of the different ways by which a cell may endocytose cargo is increasing by leaps and bounds. In this review we explore pathways of endocytosis that occur in the absence of clathrin. These are referred to as clathrin-independent endocytosis (CIE). Here we primarily focus on those pathways that function at the small scale in which some have distinct coats (caveolae) and others function in the absence of specific coated intermediates. We follow the trafficking itineraries of the material endocytosed by these pathways and finally discuss the functional roles that these pathways play in cell and tissue physiology. It is likely that these pathways will play key roles in the regulation of plasma membrane area and tension and also control the availability of membrane during cell migration.

\begin{abstract}
The identification of many of the components
involved in clathrin-mediated endocytosis (CME) and their subsequent characterization have provided a window into how this complex process works. For example, understanding how a clathrin basket is assembled, and how adaptor complexes, the mechanochemical GTPase dynamin, and Rab GTPases work have given us insights into endocytic pit formation, cargo concentration, vesicle scission, and subsequent trafficking. These topics are described in detail elsewhere in this volume (see Johannes et al. 2014; Kirchhausen et al. 2014; Merrifield and Kaksonen 2014).
\end{abstract}

Consequently, CME has remained a predominant paradigm for following the uptake of material into the cell. Several endocytic pathways that do not use clathrin and its attendant molecular machinery have begun to be recognized as distinct clathrin-independent endocytic pathways (CIEs) (see Fig. 1). Some of these pathways are constitutive, whereas others are triggered by specific signals or are even hijacked by pathogens. In addition, they differ in their mechanisms and kinetics of endocytic vesicle formation, associated molecular machinery, and cargo destination. Here we discuss characteristics of clathrin-independent (CI) endocytic

Editors: Sandra L. Schmid, Alexander Sorkin, and Marino Zerial

Additional Perspectives on Endocytosis available at www.cshperspectives.org

Copyright (C) 2014 Cold Spring Harbor Laboratory Press; all rights reserved; doi: 10.1101/cshperspect.a016758

Cite this article as Cold Spring Harb Perspect Biol 2014;6:a016758 
S. Mayor et al.

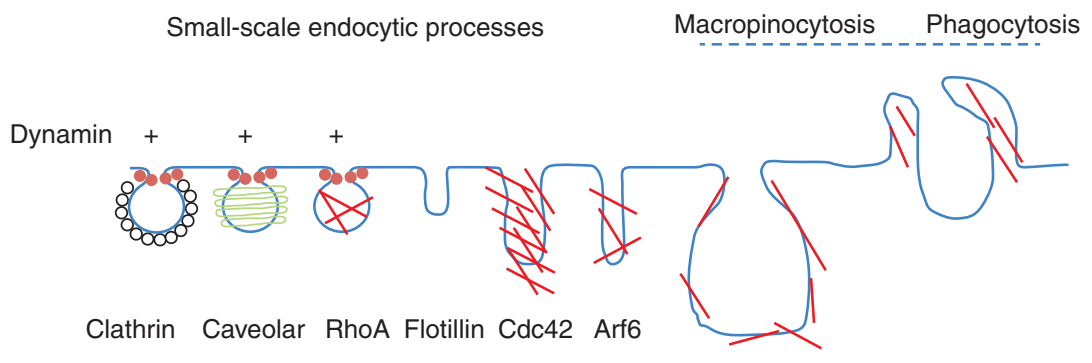

Figure 1. The diversity of endocytic pathways available at the cell surface of metazoan cells. The schematic outlines multiple means by which a cargo located at the plasma membrane or in the extracellular milieu enters the endocytic pathway in metazoan cells. Dynamin-dependent pathways $(+$; circles $)$ are typically associated with small-scale coat-mediated invaginations, such as clathrin or caveolar pathways. The dynamin-independent pathways reflect a larger diversity of forms, ranging from the small-scale processes to the larger scale membrane invaginations. The main effectors of the CIE pathways are indicated below their primary invaginations. All the dynamin-independent mechanisms appear to use actin filament (red bars) polymerization machinery.

pathways, the logic and mechanisms of cargo selection, vesicle budding, the itineraries of internalized cargo, and provide a perspective on the regulation of CIE.

At first glance CIE facilitates two types of endocytic processes-the large micrometerscale pathways such as macropinocytosis and phagocytosis, and a spectrum of smaller $(<200 \mathrm{~nm})$ scale processes (Fig. 1). The largescale processes involve internalization of significant patches of membrane, but these pathways may share some of the same molecular machinery as the smaller scale processes, especially those utilizing actin machinery in membrane remodeling, and have been addressed in recent reviews (Flannagan et al. 2012; Bohdanowicz and Grinstein 2013; see also Cossart and Helenius 2014).

\section{SMALL-SCALE CIE PROCESSES}

The physical demands of bending membrane at small scales, and trapping specific cargo creates distinct problems to be resolved when the scale of the membrane shrinks below $200 \mathrm{~nm}$, especially when relatively rigid scaffolds such as the clathrin coat are not used. This is in part owing to the bending modulus of the membrane becoming a major determinant in the endocytic process (see Johannes et al. 2014), and the necessity of trapping diffusible cargo in small regions of the membrane undergoing inter- nalization. These requirements place endocytic pathways that operate without clathrin into a distinct category.

A simple classification scheme for the smallscale CIE pathways was attempted earlier (Mayor and Pagano 2007) and still remains a useful one (Fig. 1). The requirement for dynamin neatly divides those that use dynamin (dynamin-dependent) from those that require other machinery (dynamin-independent). Another important classifier is the presence or absence of a coat that marks the internalized patch of membrane, and in those that lack a defined coat, it is the small GTPases that regulate actin that are often involved in mediating CIE. The division of CIE pathways into subclasses is not to set up rigid categories but to provide a framework to organize and discuss emerging data in this rapidly growing field and to fuel systematic experimentation. It is clear that there are common themes and this will be discussed at the end of this work.

We begin our discussion on the small-scale CIEs with the best-studied non-clathrin-coated representative, the dynamin-dependent caveolar endocytic system.

\section{CAVEOLAE: PLASMA MEMBRANE PITS POISED FOR ENDOCYTOSIS?}

Caveolae in nonmuscle cells are characterized by $\sim 140$ molecules of the oligomeric integral 
membrane protein, caveolin-1 (CAV1), 3070 mol of caveolin-2 CAV2), and a complex of peripheral membrane proteins, now termed cavins (Hansen and Nichols 2010; Hayer et al. 2010a; Parton and Del Pozo 2013). Cavins 1, 2, and 3 associate with the caveolae of mammalian nonmuscle cells. In skeletal muscle cells, caveolin-3 (CAV3) replaces the caveolin-1/2 complex and an additional cavin family member, cavin4/MURC, associates with the cavin complex (Way and Parton 1995; Ogata et al. 2008; Tagawa et al. 2008; Bastiani et al. 2009).

A long-standing question in the field has been the endocytic potential of caveolae. How dynamic are caveolae, particularly in comparison to clathrin-coated pits, and are they endocytic at all? If so, what machinery is involved and does it share components with other endocytic pathways? Do they differ in their dynamics in different tissues and in different regions of the same cells? And of course, what is the function of caveola internalization; are there a set of cargoes that are dependent on caveolae for entry into cells or does caveolar endocytosis serve some other purpose? When considering these questions we must also be aware of the dramatic differences in caveolar density in different cell types (and even within the same cell type in different tissues, e.g., brain versus cardiac endothelia) (Simionescu et al. 2002), pointing to considerable cell-type-specific functions in contrast to the ubiquitous clathrin-coated pits (Parton and Del Pozo 2013). The relatively mild phenotype observed in caveolin-deficient mice (Drab et al. 2001; Park et al. 2002) is also consistent with specialized functions of caveolae and/or significant compensation, rather than a universal essential cellular function.

\section{Caveolae as Endocytic Carriers}

It is now clear that caveolae can detach from the plasma membrane to form an endocytic caveolar carrier. Earlier studies using green fluorescent protein (GFP)-CAV1 and CAV1-GFP suggested caveolae were relatively immobile, at least compared with clathrin-coated pits, although internalization could be stimulated by treatment with a general phosphatase inhibitor (Thomsen et al.
2002) in agreement with earlier studies (Parton et al. 1994). Subsequent work defined the steady-state kinetics of caveolae in more detail and reported two distinct pools: a majority that is immobile, and a minority displaying a fast "kiss-and-run" behavior involving transient fusion without full collapse of the vesicle with lifetimes of 2-5 sec (Pelkmans and Zerial 2005). A recent study using stable cell lines expressing low levels of CAV1-GFP studied at $37^{\circ} \mathrm{C}$ was combined with examination of cavins and electron microscopy (Boucrot et al. 2011). Cavin1 appears to represent a particularly good marker of caveolae as cavin1 does not bind to CAV1 in transit through the secretory pathway or if caveolae are disassembled (Hill et al. 2008). These studies provided further important insights into the dynamics of caveolae in a cultured cell line. In interphase cells $85 \%$ of caveolae were internalized as defined by loss of CAV1-GFP fluorescence in the TIRF plane, in the $10 \mathrm{~min}$ observation period (Boucrot et al. 2011). Lifetimes ranged from $<2 \sec (30 \%$ of caveolae) to $>7$ min. Budded structures were cavin-positive, providing independent evidence for their identification as endocytic caveolar carriers (Boucrot et al. 2011). Boucrot et al. further showed that despite different lifetimes at the plasma membrane, budding and fusion back to the plasma membrane showed similar kinetics (within $1 \mathrm{sec}$ ). Importantly, these detailed kinetic studies were complemented by studies of caveolar density and caveolar budding by electron microscopy (EM) (Boucrot et al. 2011).

Generally similar conclusions can be derived from other recent studies that have used a combination of complementary techniques (Boucrot et al. 2011; Moren et al. 2012; Stoeber et al. 2012) that seem to contradict the earlier studies that concluded that caveolae are not constitutively budding endocytic carriers (Thomsen et al. 2002). Importantly, the recent studies also showed agreement on the dependence on dynamin function, both using small molecule inhibitors and dominant-negative inhibitors (Boucrot et al. 2011; Moren et al. 2012; Stoeber et al. 2012). From these studies we can therefore conclude that current evidence would suggest a dynamic cycle of caveolae budding from the 
S. Mayor et al.

plasma membrane, some of which fuse with the plasma membrane (PM) in an apparent futile cycle, whereas others reach the early endosome and then return as a stable entity to the PM. The dynamic nature of caveolae is supported by studies of caveolae in endothelia in vivo ( Oh et al. 2007). In these live imaging experiments caveolae were not followed by using a fluorescent caveolin fusion protein but using antibodies to an endogenous surface marker of caveolae, the glycosylphosphatidylinositol-anchored protein (GPI-AP) aminopeptidase P (Oh et al. 2007). These studies showed a remarkable ability of caveolae to mediate rapid transendothelial transport in the lung. Transport was blocked by down-regulation of CAV 1 and did not occur with other surface markers that were not concentrated in caveolae (Oh et al. 2007). The kinetics of the transport were consistent with very rapid endocytosis via caveolae in endothelial cells, similar or even faster than that mediated by clathrin-coated pits. Taken together with the studies of caveolin-GFP fusions and parallel electron microscopic studies we can conclude that caveolae are indeed dynamic endocytic carriers.

The machinery involved in caveolae endocytosis is gradually emerging. In addition to the GTPase, dynamin, localized to the neck of caveolae (Henley et al. 1998; Oh et al. 1998, 2012; Boucrot et al. 2011), we can now add the ATPase EHD2, and the F-BAR-domain protein pacsin2. In contrast to dynamin, EHD2 is a negative regulator of endocytosis; budding of caveolae is increased by knockdown of the ATPase EHD2 (Moren et al. 2012; Stoeber et al. 2012). Again, this was shown by both light microscopy (total internal reflection fluorescence microscopy [TIRF] and photobleaching) and by electron microscopic caveolar endocytic assays strengthening the conclusions that bona fide caveolar budding was being observed (Moren et al. 2012; Stoeber et al. 2012). The mechanism by which EHD2 inhibits caveolar endocytosis is not yet known but the actin cytoskeleton has been implicated in providing the EHD2-dependent inhibitory constraint. Caveolae align along actin filaments and real-time observation of drug-induced redistribution of actin showed that EHD2 followed the reorganizing actin cytoskeleton in WT cells but not in cells with down-regulated EHD2 (Stoeber et al. 2012). This implicated EHD2 directly or indirectly, in linking caveolae to actin. A mutated form of EHD2 with accelerated ATPase activity showed actin association even in cells lacking CAV1 suggesting that the ADP form of the protein might link to actin independently of caveolae. The full ATPase cycle would be required to provide a regulated link between caveolae and the actin cytoskeleton. In cells with caveolae this mutant shows more stable association with caveolae and displacement of endogenous EHD2 (Stoeber et al. 2012). Interaction with actin may not be direct and a number of candidate actin-binding proteins, including filaminA (Muriel et al. 2011), have been linked to caveolae; depletion of filamin A increases caveolar dynamics and disrupts stable anchoring of caveolae (Sverdlov et al. 2009; Muriel et al. 2011). Like dynamin, EHD2 appears to be associated mainly with the neck of caveolae (Ludwig et al. 2013).

EHD2 also interacts with Pacsin2 (PKC and casein kinase substrate in neurons 2), another key regulator of caveolar formation (Hansen et al. 2011; Senju et al. 2011). Pacsin2 binds both dynamin and CAV1 and is a BAR-domain-containing protein, able to sense and modulate membrane curvature. In addition to these components, studies of endothelial cells have identified various components of the cellular membrane fusion machinery including NSF, SNAP, and VAMP2 (Schnitzer et al. 1995; McIntosh and Schnitzer 1999). The latter appeared to be a major component of isolated caveolae and was shown to be required for endothelial uptake of cholera toxin via caveolae (Schnitzer et al. 1995).

\section{OTHER DYNAMIN-DEPENDENT CIES}

\section{The IL-2 Receptor Endocytic Route}

As indicated above, a number of CI pathways that operate at the small scale $(0.1-1 \mu \mathrm{m})$, function to internalize specific cargo. In this category there are dynamin-dependent pathways and dynamin-independent pathways. 
A well-studied example of the first category is the RhoA-dependent IL-2 receptor endocytic route (Lamaze et al. 2001; Gesbert et al. 2004). EM studies confirm that IL-2 receptors are concentrated and then internalized via small noncoated invaginations. Both the specific concentration of the receptors and uniform size $(50-100 \mathrm{~nm})$ of the endocytic vesicle indicate the presence of an as-yet-unidentified protein coat that could aid in the recruitment of these proteins to the site of endocytosis, and mold the endocytic pit.

Many cytokine receptors and their constituents, such as the $\beta$ chain of the interleukin 2 and 15 receptors (IL-2R $\beta$ ) and the common cytokine $\gamma$ chain (IL-2R $\gamma \gamma$ ) of the receptors for interleukins 2, 4, 7, 9, 15, and 21 use this route (Gesbert et al. 2004). Here dynamin regulates endocytosis via an endocytic pathway that is cholesterol sensitive, wherein many IL receptor subunits associate with "lipid raft"-like domains (Lamaze et al. 2001). It is likely that in this domain, an actin-based machinery, involving cortactin and neuronal Wiskott-Aldrich syndrome protein (N-WASP) is assembled to facilitate IL-2R entry. This is regulated by input from a IL-2R-activated PI3P signaling cascade that in turn activates RhoA, and consequently Rac1 (Basquin et al. 2013). Subsequently p21-activated kinase 1 (Pak1), a downstream target of Rac1, phosphorylates cortactin, promoting its interaction with N-WASP (Grassart et al. 2008, 2010). This cascade facilitates the recruitment and activation of a complex composed of cortactin, N-WASP, Arp2/3, followed by generation of F-actin during IL-2R endocytosis. Amyloid precursor protein (APP) endocytosis in primary neurons (Saavedra et al. 2007) is another example of this pathway.

\section{Endocytosis of the EGF Receptor}

In the context of the (epidermal growth factor EGF) receptor (EGFR), at low doses of EGF the receptor is directed toward a clathrin-dependent pathway, and at high doses it appears that it uses a CI pathway (Sigismund et al. 2005). Enhanced ligand-dependent ubiquitination of the receptor has been suggested to act as a regu- latory switch that shunts the receptor toward a clathrin-independent endocytic route, and this likely involves a ubiquitin adaptor for endocytosis (Sigismund et al. 2013). The endocytosis of EGFR at high concentrations of EGF requires cholesterol and "raft" association of the EGF receptor similar to the IL-2 receptor above. Here the role of dynamin remains controversial because in separate studies at high concentrations of EGF, dynamin inhibition appeared to inhibit endocytosis (Sigismund et al. 2005), or had no effect on EGF internalization (Jiang and Sorkin 2003). The role(s) of actin machinery here is poorly characterized; the activity of N-WASP (Benesch et al. 2005) is important, and RhoA (Nishimura et al. 2011) and cortactin (Timpson et al. 2005) have also been implicated, albeit as negative regulators of EGFR endocytosis.

\section{COAT- AND DYNAMIN-INDEPENDENT ENDOCYTIC PROCESSES}

Given the accumulating body of literature on clathrin, and now caveolar endocytosis (see above), it is much easier to conceptualize a dedicated protein deformation machinery assembling at the inner surface of the cell, governing the endocytic process. This coat in turn could act as molecular flypaper to concentrate endocytic cargo, and where studied, the pathways have been shown to require the function of dynamin to affect the endocytic process. Endocytosis in the absence of identifiable coats poses multiple problems. However, it is now well established (despite major debates [Mayor and Pagano 2007; Howes et al. 2010b; Kumari et al. 2010]), that there are a number of endocytic pathways in which neither specific coat proteins nor a particular pinching machinery have been identified.

As early as the 1980s researchers realized that bulk phase markers (such as Lucifer yellow or the cell-surface-binding lectin, ricin) could be endocytosed in cells where clathrin function was inhibited by a number of physicochemical means (Moya et al. 1985; Doxsey et al. 1987; Sandvig and van Deurs 1994). Later studies used molecular genetic tools to confirm these observations (Damke et al. 1994; Sabharanjak 
S. Mayor et al.

et al. 2002), and establish the existence of dynamin-independent endocytosis. Unimpaired fluid phase endocytosis in primary hemocytes derived from the temperature-sensitive shibire mutants of Drosophila (Guha et al. 2003) in which the mutant dynamin gene in Drosophila renders all dynamin splice forms temperature sensitive because it is located in the exon encoding the common GTPase domain (Grant et al. 1998), also provides convincing evidence for dynamin-independent endocytosis.

In the absence of a defined coat, recent evidence suggests that specific lipid accumulation (reviewed in Johannes and Mayor 2010) or accretions of almost any membrane-tethered protein (Stachowiak et al. 2012), could initiate membrane deformation by physically making the membrane bud and form a vesicle, by an energetically favorable process. For example, Shiga toxin entry is initiated by binding of toxin to the ganglioside, Gb3. This induces invaginations in cells as well as model membranes as a result of its specific organization as a heptameric toxin recruiting multiple $\mathrm{Gb} 3$ species into close proximity (Romer et al. 2007), leading to a compaction of lipid species into a specific geometry. To relieve line tension, these lipid clusters aggregate and favor the formation of a membrane bud. An example in which a protein accretion initiates endocytosis is the process of HPV16 virus infection, in which tetraspannin-enriched domains are recruited for virus entry (Spoden et al. 2008).

\section{The CLIC/GEEC Pathway}

Endocytosis of lipid-anchored proteins such as GPI-APs does not use any detectable protein coat; there is a lack of any electron-dense material surrounding the earliest detectable endocytic intermediates by EM visualization (Kirkham et al. 2005). Together with the highly pleiomorphic nature of the endocytic intermediates, this suggests that if there are coats, they are too transient to be captured by current methodologies of cell fixation and processing and would allow a whole plethora of membrane morphologies. GPI-APs are endocytosed via a dynamin-independent endocytic route, into a specialized early endosomal compartment that also accommodates a major fraction of internalized fluid phase (Sabharanjak et al. 2002). These endocytic structures containing endocytosed GPI-APs are termed GEECs (GPI-AP enriched early endosomal compartments), and they result from fusion of the primary uncoated CI tubulovesicular carriers called CLICs (CI carriers), which are directly derived from the cell surface (Kirkham et al. 2005). The process is thereby termed the CLIC/GEEC (CG) pathway.

The CG pathway is a high-capacity pathway in which most of the internalized fluid phase is delivered to the cell, in a process that is distinct from macropinocytosis (because it is a constitutive process, and not sensitive to amilioride, a selective inhibitor of macropinocytosis). In many cell types it is also responsible for the rapid recycling of the membrane area of the cell; in mouse embryonic fibroblasts, the entire cell surface is recycled in $<15$ min (Kirkham et al. 2005). Although GEECs appear enriched in GPI-APs (Sabharanjak et al. 2002), the mechanism for selectively enriching the outer leaflet tethered GPI-APs in CLICs is not well understood. A lipid-based sorting mechanism has been proposed because alterations in cholesterol and sphingolipid levels as well as perturbation of the nanoclustering of GPI-AP affects endocytosis via this pathway (Sharma et al. 2004; Chadda et al. 2007). The size of the extracellular moiety attached to the lipid tail may act as an additional determinant for inclusion into GEECs (Bhagatji et al. 2009). Additionally, several transmembrane proteins such as CD44 and dysferlin are also selectively endocytosed via this pathway (Howes et al. 2010a).

The molecular machinery of the CG pathway is apparently initiated by the recruitment of GBF1, a guanine nucleotide exchange factor (GEF) for Arf 1, at the cell surface (Gupta et al. 2009), which in turn serves to activate Arf1. Activated Arf1 in turn recruits ARHGAP10/21, a RhoGAP, to the cell surface (Kumari and Mayor 2008) or vice versa. This complex machinery is used to maintain the RhoGTPase Cdc42 in its cycling state to effect the recruitment of downstream actin polymerization machinery. Dynamic actin polymerization is necessary for en- 
docytosis, and is maintained by Cdc42 dynamics at the PM (Chadda et al. 2007; Kumari and Mayor 2008). Another recently reported effector of GEEC formation is the multidomain protein GTPase regulator associated with focal adhesion kinase1 (GRAF1), which has a BAR domain, SH3 domain, and a Rho-GAP domain. It colocalizes to CG carriers in HeLa cells where its loss results in reduced CG uptake (Lundmark et al. 2008). Additionally, GRAF1 colocalizes with active Cdc42 and also contains a Rho-GAP domain, thereby ensuring a loss of Cdc42 activity, along with ARHGAP10/21. The roles of the BAR domain, which could aid in generating membrane curvature, and the SH3 domain, capable of interacting with dynamin GTPase, are yet to be explored. Although CLIC formation is dynamin-independent, dynamin is localized to GEECs postinternalization (Kirkham et al. 2005), and this is necessary in some cell types for recycling of the membrane internalized into GEECs. This step could be mediated by GRAF1.

At this time it is not clear if there are multiple mechanisms that function in a similar coat-independent fashion to form CLICs and deliver cargo to the GEECs.

\section{ARF6-Associated Pathway}

Another mode of CIE that is also dynamin-independent is one that was originally identified owing to its association with Arf6 (Radhakrishna and Donaldson 1997). Arf6 is present at the cell surface and in many cells on endosomes that contain CIE cargo proteins. A wide variety of endogenous cell-surface proteins have been identified that enter cells by this pathway that include proteins involved in nutrient transport (Glut1, CD98, Lat1), in matrix interaction (CD44, CD147), in immune function (MHC Class I, CD1a), and proteins anchored to the membrane by GPI (CD55 and CD59) (Eyster et al. 2009; Maldonado-Baez et al. 2013b). Internalization is clathrin- and dynamin-independent, but cholesterol-dependent. The incoming endosomes are distinct from the clathrin-dependent cargo-containing endosomes but soon after internalization they fuse with Rab5-positive sorting endosomes (Naslavsky et al. 2003) where they are sorted for recycling or degradation (see section below).

Arf6 activation and inactivation modulates membrane trafficking in this pathway (Grant and Donaldson 2009) mediated in part by Arf6 activation of phosphatidylinositol-4-phosphate 5-kinase. In most cases, Arf6 activation is not required for endocytosis, but is required for recycling. In contrast, Arf6 inactivation is required soon after internalization for sorting of endosomal cargo as overexpression of the constitutively active form of Arf6 traps cargo in internal vacuolar structures that are coated with phosphatidylinositol-4,5-bisphosphate (PIP2) (Naslavsky et al. 2003). It is important to note that the Arf6-stimulated generation of PIP2 at the PM can also indirectly affect other endocytic events. In particular because CME requires PIP2, increased Arf6-GTP can sometimes enhance or facilitate CME.

The ARF6-associated pathway bears resemblance to the CLIC/GEEC pathway in that these pathways internalize similar cargo (Eyster et al. 2009; Howes et al. 2010a). The CG pathway and the Ar6 pathway have been considered as separate (Fig. 1) (see also Doherty and McMahon 2009); however, it is not certain if they represent the same or distinct process. In cells in which the CG pathway has been shown to function, Arf6 plays little or no role in endocytosis of the CG cargo (Kumari and Mayor 2008); however, the reverse experiment has yet to be performed. It is likely that these two processes could use similar mechanisms for initial entry, and the association with specifically activated Arf6 with these endocytic vesicles in the context of specific cell types generates a distinct endosomal trafficking system.

\section{Other Dynamin-Independent Endocytic Pathways}

Flotillins appear to outline yet another dynamin- and clathrin-independent endocytic process, because cargo including fluid phase and a GPI-anchored protein CD59 in HeLa cells are endocytosed via this pathway (Glebov et al. 2006). In the cells depleted of flotillin1, there is a defect in uptake of CD59, and CTxB inter- 
nalization is shifted to a dynamin-dependent mode. There are two flotillin genes, flotillin 1 and 2 (identical to Reggie 2 and 1, respectively) (Babuke and Tikkanen 2007), and flotillin 1 and 2 appear to induce membrane invaginations in a dose-dependent manner (Frick et al. 2007). In addition the nonreceptor tyrosine kinase fynmediated phosphorylation of flotillin appears to trigger endocytosis via this pathway (Riento et al. 2009). Recently, Lencer and colleagues found that cholera toxin intoxication of zebrafish embryos and mammalian cells requires flotillin (Saslowsky et al. 2010). However, Sandvig and coworkers found that in the case of Shiga toxin and ricin, flotillin depletion increases toxicity (Pust et al. 2010). Although in all these toxins, intoxication requires delivery of the toxin to the ER, the differential responses to flotillin depletion indicates a more complex requirement for this protein, potentially in multiple locations in the endocytic pathway. Furthermore, although flotillins may define yet another dynamin-independent endocytic process, there are studies that suggest that dynamin may be involved in endocytosis of cargo that require flotillin (Otto and Nichols 2011). This has been rationalized by suggesting that flotillins could act as adaptors for specific cargo, tracking them to alternative dynamin-dependent endocytic routes. Thus, until additional molecular machinery is identified, the function of endogenous flotillins in endocytosis, their capacity to interact with specific cargo, and the mechanism of vesicle generation remain unresolved.

The antagonist of the nicotinic acetylcholine receptor, $\alpha$ bungarotoxin, induces internalization of its target, via a relatively slow dynamin-independent process. This proceeds via a mechanism dependent on local actin polymerization triggered by antagonist-induced activation of the nonreceptor tyrosine kinase c-src that in turn activates the Rac1 GTPase and subsequently promotes actin polymerization; inhibition of Racl activity or actin polymerization inhibits endocytosis of the nicotinic receptor (Kumari et al. 2008). A similar pathway is triggered by the HIV Nef protein to down-regulate the costimulatory proteins CD80 and CD86 in macrophages to render infected macrophages incapable of activating naïve $\mathrm{T}$ cells (Chaudhry et al. 2007).

\section{A Central Role for Actin Polymerization in the Absence of Clathrin and Dynamin}

There is a breathtaking diversity in the cargo and the molecular machinery behind clathrinand dynamin-independent endocytic systems (Conner and Schmid 2003; Mayor and Pagano 2007; Sandvig et al. 2008; Doherty and McMahon 2009). If there is any generalizable mechanism for endocytosis in the absence of both clathrin and dynamin, it is the role of specialized actin-based platforms that emerges as a unifying mechanism to aid in this form of endocytosis. Indeed perturbation of actin polymerization by using inhibitors of polymerzation or depolymerization has been shown to inhibit the formation of CLICs in a number of these pathways. A recent study shows that actin reorganization is necessary for the scission of membrane tubules generated via the assembly of lipid nanoassemblies in vitro (Romer et al. 2010). It is more complicated to assess the role of actin polymerization in the cell because it is also involved in the assembly of the lipid and protein assemblies, itself (Gowrishankar et al. 2012).

Mechanistically, there may be many ways to recruit and assemble actin machinery to affect endocytosis; therefore these pathways have distinct upstream mechanisms of initiating the endocytic process, depending on the nature of cargo and the mechanism for its selection. This may involve the recruitment of actin polymerization regulators; for example, Cdc42 for the CG pathway, RhoA for the IL-2R pathway, Rac for the nicotinic receptor and the CD80 and 86 proteins, and so on. However, all these pathways may share a common downstream signature that revolves around the assembly and deployment of actin polymerization to affect the actual endocytic process.

\section{Endocytosis Mediated by the Actin Cytoskeleton: A Case Study}

To understand this downstream role of the actin machinery in endocytosis, it may be useful to 
focus on one system in which this pathway is best understood, namely, in the genetic system yeast (Galletta and Cooper 2009). Although endocytosis in yeast is defined as a clathrin-mediated process, clathrin itself is dispensable for endocytosis in yeast (Payne 1990; Munn et al. 1991; Tan et al. 1993), and subsequent studies have shown that although clathrin facilitates endocytic site assembly, it is not required for membrane invagination or vesicle formation. In a mutant screen for endocytic defects in yeast, actin and its regulators were the prime hits; one-third of the endocytic proteins identified in this screen bind actin or regulate its assembly (Munn et al. 1995). Therefore, the role of actin in almost every stage of this pathway provides a way to understand how actin may play a specific role in endocytosis (Weinberg and Drubin 2012). With the visualization of the recruitment of actin to the sites of endocytosis in live cells (Toret and Drubin 2006), Drubin and colleagues have systematically identified actin patches, which have distinct protein composition and motility properties, and accumulate in the different genetic mutants as intermediates in the endocytic process (Kaksonen et al. 2003, 2005). This allowed a dissection of the endocytic pathway into four stages representing distinct protein modules involved in coat formation, membrane invagination, actin-meshwork assembly, and vesicle scission (also see Merrifield and Kaksonen 2014).

Based on these studies and more recent correlative light and electron microscopy, followed by EM-based tomography, it appears that endocytosis is initiated at a site where the membrane invaginates and then is elongated into a tube by active polymerization of actin and traction by myosin motors (Geli and Riezman 1996; Kukulski et al. 2012). This culminates in the scission of this tube by a mechanochemical process (Liu et al. 2006). Here it is proposed that distinct membrane domains are created by the action of lipid kinases and phosphatases acting differentially on the neck and stalk of the tube; the resultant line tension between these domains is a cause for scission. This is a mechanochemical model because it is the generation of the elongated and narrow neck of the endocytic tube that differentially recruits lipid kinases and phosphatases, resulting in a kinetic segregation of lipids in the neck region. Although interesting as a model, several tests need to be performed before its validity may be ascertained, but it does provide an actin-centric way of looking at the endocytic process.

\section{POSTENDOCYTIC TRAFFICKING OF CIE CARGO PROTEINS}

After entry, newly formed endocytic structures arising from CIE can undergo rounds of homotypic fusion followed by heterotypic fusion with endosomes arising from CME. The tracking of incoming endosomes from CIE to assess what endosomes they fuse with and how they acquire particular endosomal Rab proteins is an experimental challenge and data on this is incomplete. Further complicating this is the variety of types of both clathrin-independent and -dependent forms of endocytosis and how these membrane systems manifest themselves in different cell types.

A consensus has emerged from real-time studies that the destination for budded caveolae is the early endosome (Pelkmans et al. 2004; Hayer et al. 2010a; Boucrot et al. 2011; Stoeber et al. 2012), a conclusion actually reached in earlier ultrastructural studies (Montesano et al. 1982; Tran et al. 1987; Parton et al. 1994). Previous reports of a specialized endosomal compartment receiving internalized CAV1, termed the "caveosome," have been explained as an artifactual late endosomal destination of overexpressed caveolin (Hayer et al. 2010a). The use of fluorescently tagged cavin with CAV 1 in light microscopic experiments helped establish that caveolae travel to early endosomes (Hayer et al. 2010a; Boucrot et al. 2011). Cavin-labeled vesicles are readily observed by EM in the cytosol of cultured cells, as well as on putative endosomal structures (Hayer et al. 2010b), consistent with observations of caveolin forming a stable domain on the early endosome from which cargo, including cholera toxin, is released (Pelkmans et al. 2004). In contrast, EHD2 is not detectable on the early endosome (Stoeber et al. 2012). 
S. Mayor et al.

There is compelling evidence in the CG pathway that the incoming endosomes have the capacity for homotypic endosomal fusion and subsequent sorting of cargo. In some cell lines, $\sim 50 \%$ of the newly endocytosed material is recycled at this early stage, and the remaining membranes fuse to mature into GEEC structures. The initial fluid and membrane-containing endocytic structures become highly acidic, and acquire PI3P, Rab5, and the early endosomal antigen 1 (EEA1) (Kalia et al. 2006). Both the morphology and highly acidic nature of the GEEC suggest that this endosome could begin to sort cargo and membrane for different destinations (Sabharanjak et al. 2002; Howes et al. 2010a), before delivery of material to the early sorting endosome (Fig. 2).

In the Arf6-associated pathway, the incoming endosomes can undergo homotypic fusion stimulated by Arf6-GTP and phosphatidylinositol-4,5-bisphosphate (PIP2) (Brown et al. 2001) but further trafficking toward recycling or degradation requires inactivation of Arf6, loss of PIP2, and acquisition of Rab5 and PI3P (Brown et al. 2001; Naslavsky et al. 2003). Recycling of endosomal membrane back to the PM requires Arf6 in a number of cell systems (Radhakrishna and Donaldson 1997; Powelka et al. 2004; Balasubramanian et al. 2007).

Regardless of the specific mode of cellular entry, endosomes containing CIE cargo proteins eventually fuse with the early or sorting endosome (SE) that contains CME-derived cargo proteins (see Fig. 2). Although sorting occurs throughout the endosomal pathway, the "classical" SE is defined by the presence of Rab5, PI3P, and EEA1. Recent work by Zerial and colleagues suggests more variety in the composition of

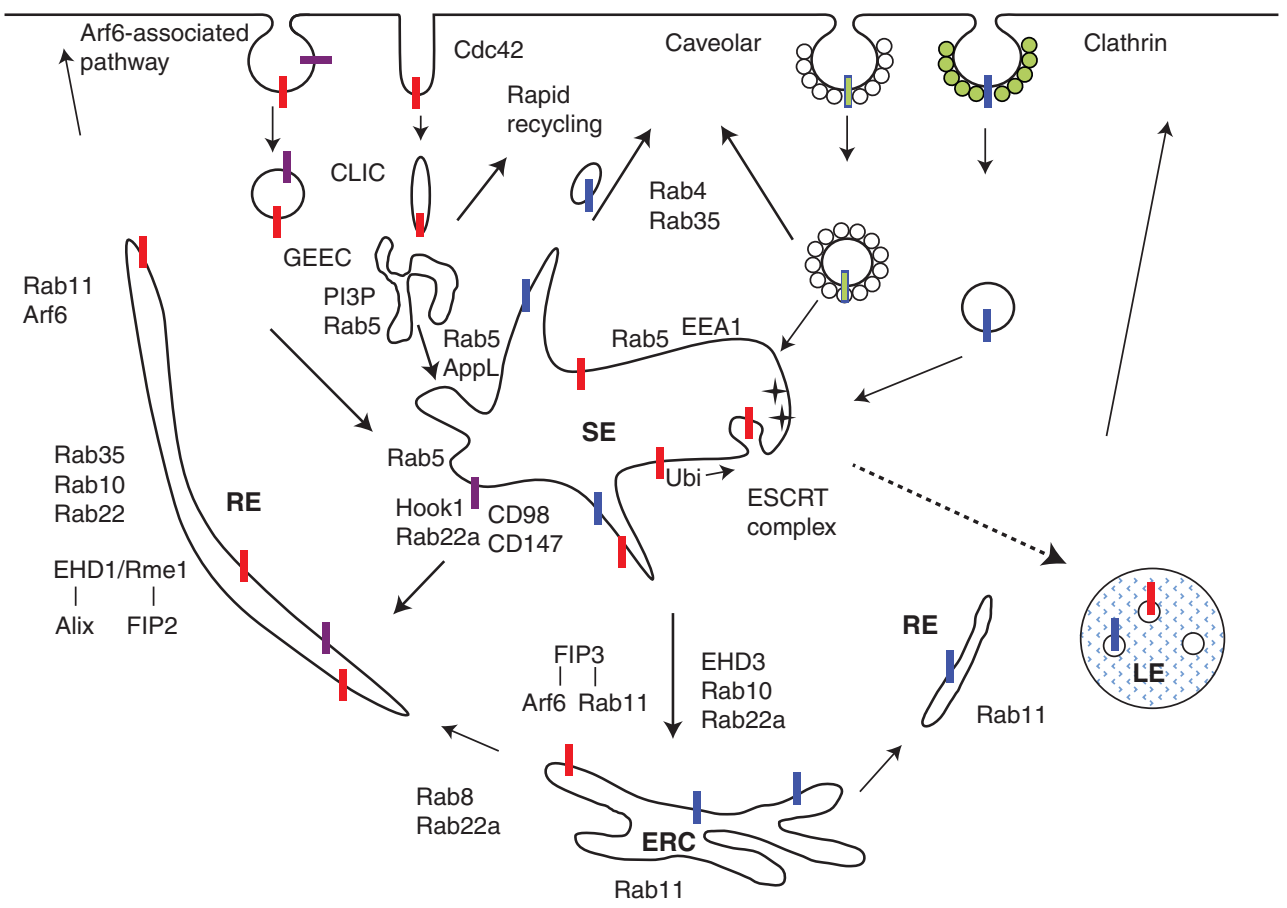

Figure 2. Trafficking itineraries of endocytosed cargo in a typical mammalian cell. The diagram maps the trafficking itineraries of cargo endocytosed via multiple means including the clathrin-mediated pathway (see text for details). A number of endocytic compartments and destinies are available for cargo endocytosed via the CIE, whereas clathrin and caveolar pathways typically deliver their cargo directly to the sorting endosomal system. The CIE pathways often use distinct molecular machinery and separate recycling compartments to return cargo internalized via these routes. 
these compartments including those with Rab5 only, Rab5 and APPL positive, and Rab5 and EEA1 positive (Miaczynska et al. 2004). For simplicity, here we depict the SE as a large composite structure with differentiation of distinct domains enriched in particular membrane lipids and Rab proteins. Fusion with this compartment requires the acquisition of $\mathrm{PI} 3 \mathrm{P}$ and Rab5 (Naslavsky et al. 2003; Kalia et al. 2006). Once in this compartment CIE cargo proteins now join cargo entering through CME and further sorting of cargo can occur. Through the process of maturation and release of transport carriers, cargo proteins and membrane can proceed toward late endosomes and lysosomes, the trans-Golgi network, or to recycling endosomes. Also trafficking into and through this compartment are CME cargo proteins such as transferrin and LDL receptors. Endosomal trafficking and sorting is discussed in more detail elsewhere in this volume (see Henne et al. 2013; Burd and Cullen 2014; Klumperman and Raposo 2014); therefore, here we focus on the sorting and trafficking of CIE proteins.

The final destination of internalized membrane and cargo varies with the type of CIE, particular cargo proteins, and cell type. The contents of GEECs proceed to the juxtanuclear recycling compartment in Chinese hamster ovary (CHO) cells and fibroblasts (Sabharanjak et al. 2002), and to late endosomes and lysosomes in baby hamster kidney (BHK) cells (Fivaz et al. 2002). In mouse embryonic fibroblasts, CD44 enters GEECs and is sorted away to reside in a long-lived compartment that is distinct from the recycling compartment as well as late endosomes (Howes et al. 2010a). It is likely that this pathway may use similar machinery as the Arf6 pathway to segregate out material from its degradative destination. In T cells, the IL-2 receptor that enters cells via a RhoA/Rac and dynamindependent pathway is also delivered to late endosomes for degradation (Rocca et al. 2001). Cargo entering cells through Arf6-associated CIE is sorted to recycling or degradation based on specific cytoplasmic sequences (Eyster et al. 2009; Maldonado-Baez et al. 2013b) and the presence or absence of ubiquitination on the cytoplasmic tails of these cargo proteins (Eyster et al. 2011).

\section{SORTING OF CIE CARGO PROTEINS AFTER ENDOCYTOSIS}

In HeLa cells a number of PM proteins have been identified that enter cells via CIE. The major histocompatibility complex class I (MHCI) is a prototypic cargo protein that enters in endosomes associated with Arf6, and then is found in SE associated with CME cargo, Rab5 and EEA1. From here MHCI traffics via the multivesicular bodies (MVB) pathway into late endosomes and lysosomes for degradation or is recycled back to the cell surface via elaborate recycling tubular endosomes under the control of multiple Rab GTPases. Joining the itinerary of MHCI are the glucose transporter 1 (Glut1) and the GPI-APs CD55 and CD59 (Naslavsky et al. 2004; Eyster et al. 2009). Additional CIE cargo proteins have been identified that follow an alternative itinerary after entry. Among these proteins are CD44, the hyaluronan receptor; CD98, which together with Lat1, is an amino acid transporter; and CD147 (also called EMMPRIN or basigin), which interacts with integrins and matrix metalloproteases. CD44, CD98, and CD147 enter cells with MHCI but then rapidly join recycling tubules and avoid trafficking to endosomes containing the transferrin receptor and EEA1 (Eyster et al. 2009). As a consequence of this postendocytic sorting, CD44, CD98, and CD147 avoid trafficking to lysosomes and degradation (Eyster et al. 2011). It was recently shown that cytoplasmic sequences in CD44, CD98, and CD147 are responsible for this altered trafficking and that the microtubule and cargo-binding protein Hook1 facilitates this altered trafficking in coordination with Rab22a and microtubules (MaldonadoBaez et al. 2013a). CD44 and CD98 are also present as cargo proteins in the CLIC/GEEC pathway (Howes et al. 2010a) and so it will be interesting to see whether they are also differentially trafficked by Hook1 and Rab22a.

Other CIE cargo proteins have been identified that have specific amino acid sequences that facilitate recycling back to the cell surface. The inwardly rectifying potassium channel, Kir3.4, contains cytoplasmic clusters of acidic amino acids that facilitate recycling (Gong et al. 
S. Mayor et al.

2007). Syndecan 1 enters cells by CIE but through its carboxy-terminal PDZ ligand it interacts with syntenin. Syntenin facilitates recycling of syndecan 1 back to the PM in a PIP2and Arf6-dependent manner (Zimmermann et al. 2001). There are likely to be many more examples of cargo-specific sorting arising from $\mathrm{CIE}$ as more CIE cargo proteins are studied. Indeed one purpose of CIE may be to sample bulk PM proteins and lipid for inspection at an endosomal station. From here misfolded or ubiquitinated proteins can be routed to degradation and other proteins that pass inspection returning to the cell surface.

Ubiquitinylation of CIE cargo proteins has a dramatic effect on their endosomal trafficking and is very likely to be the mechanism for protein quality control of cell-surface proteins (Piper and Lehner 2011). This was dramatically shown in HeLa cells expressing the MARCH8 E3 ubiquitin ligase. CD44 and CD98 are longlived proteins that enter cells via CIE but they do not reside in endosomes that label with EEA1 and do not normally traffic to late endosomes and lysosomes for degradation (Eyster et al. 2011). In cells expressing MARCH8, however, CD44 and CD98 still enter cells by CIE but now traffic to EEA1-positive endosomes and on to lysosomes for degradation (Eyster et al. 2011). The ubiquitin tag may both engage the ESCRTubiquitin recognition system and abrogate sorting signals in the cytoplasmic tails of CIE cargo proteins thus altering the itinerary and fate of the cargo proteins. Normally, the E3 ligases are balanced by deubiquitinylating enzymes, which by removing the ubiquitin would allow recycling back to the cell surface. Although the biology of the ubiquitinylation/deubiquitinylation field is still in its infancy, it promises to enhance our understanding of how endocytic cargo is examined and sorted on endosomes.

\section{MACHINERY INVOLVED IN ENDOSOMAL MATURATION AND CARGO SORTING}

Important regulators of endosomal maturation and trafficking are the Rab GTPases. There are a number of Rab proteins associated with the endosomal system (Rab4, 5, 7, 8, 9, 10, 11, 14, 22,
35), with each Rab contributing to the identity of a particular endosome or domain on an endosomal structure (see Fig. 2). Rab proteins accomplish this through their scaffolding function and ability to connect to motor proteins. A number of Rab proteins also interact with and influence activities of Arf, Rho, and other Rab proteins. Details of the specific functions provided by the Rabs have yet to be sorted out. For specific CIE cargo proteins, distinct Rabs have been shown to be important for cargo recycling. Recycling of MHCI requires Rab11, Rab22, and Arf6 activation (Radhakrishna and Donaldson 1997; Weigert et al. 2004) and CD1b requires Rab11, Rab22, Arf6, and Arl13b (Barral et al. 2012). Rab35 has been implicated in a rapid recycling pathway in both mammalian cells and in the worm (Kouranti et al. 2006; Sato et al. 2008). Interestingly Rab35 and Arf6 each recruit the other's GAP to inactivate each other. This cross talk raises interesting kinds of regulation because both are present at the cell surface, Rab35 is also present in clathrin-coated vesicles, and Arf6 has recently been observed in clathrin structures when overexpressed. A recent study reported that Rab35 promoted the recycling of E-cadherin, a cargo that can enter cells by CME or CIE, whereas Arf6 promoted the recycling of $\beta 1$-integrin (Powelka et al. 2004; Allaire et al. 2013).

In addition to the Rab proteins, there are a number of cytosolic proteins that associate with endosomes that are capable of inducing or stabilizing membrane curvature, suggesting their involvement in endosomal sorting through tubulation. The epsin homology domain family of proteins, the EHDs, was first implicated in endosomal recycling when the worm homolog Rmel was associated with transferrin recycling. There are four mammalian EHDs and they have been implicated in the recycling of $\mathrm{MHCI}$ (Caplan et al. 2002) and GPI-AP (Cai et al. 2011) in cavolae structure for EHD2 (Moren et al. 2012; Stoeber et al. 2012), and for EHD1 in the retrograde transport of shiga toxin from the endocytic recycling compartment (ERC) to the trans-Golgi network (TGN) (McKenzie et al. 2012). EHDs can serve a scaffolding function but can also oligomerize to stabilize or in- 
duce the formation of membrane tubules (Naslavsky and Caplan 2011).

Other proteins capable of tubulating membranes include those that contain BAR domains (see Burd and Cullen 2014; Johannes et al. 2014). GRAF1 is a BAR-domain protein associated with tubular invaginations that form during the CLIC form of CIE (Lundmark et al. 2008; Howes et al. 2010a). The Arf6 GAPs, ACAP1 and ACAP2, also have BAR domains and they are recruited to membranes by Rab10 (Shi et al. 2012) and Rab35 (Egami et al. 2011; Kobayashi and Fukuda 2012), respectively. Thus as ACAPs are brought onto the endosome, they may coordinately inactivate Arf6 and allow tubules to form from endosomes, sorting cargo.

\section{ROLES OF THE CIE PATHWAYS}

In a very general sense, any endocytic pathway must take up cargo, and these could lead to specific consequences for the components that are endocytosed. A number of such examples abound for all the pathways described here and we detail some of the interesting examples that suggest important general possibilities of fered by these pathways. Second, the CIE pathways offer cell-wide functionality in terms of being able to act as sensors for the physical state of the cell, and fine regulation of the local and global composition of membrane components. Finally, these endocytic pathways could help in engaging in tissue-wide properties by integrating information from many cells.

\section{Role of Caveolar Endocytosis}

As discussed above, caveolae could form endocytic devices akin to clathrin-coated pits, able to concentrate and transport specific proteins. Yet few markers seem to be completely dependent on caveolae for entry. SV40, shown to be concentrated in caveolae (Anderson et al. 1996; Stang et al. 1997; Pelkmans et al. 2001), is now known to also use other entry mechanisms (Damm et al. 2005). Studies of endothelia have provided strong evidence from various lines of work for efficient transendothelial transport via caveolae (Oh et al. 2007). Knockdown of CAV 1 provided strong support for this model (Oh et al. 2007), yet the consequences of the apparent loss of this important pathway in mice genetically deficient for CAV1 seem to somewhat contradict the essential role of caveolae that would be envisaged. Compensation can be the explanation but because these mice lack caveola-like invaginations, vesicular transport would have to occur through other pathways. An interesting example of compensation, which might provide more evidence for an endocytic role of caveolae, comes from work on a specific isoform of myosin VI (Puri 2009). Loss of this protein blocks transferrin uptake through clathrin-coated pits but, remarkably, transferrin receptors are instead concentrated in AP2-positive caveolae, which mediate transferrin uptake (Puri 2009).

TGF- $\beta$-receptor internalization has also been linked to caveolae. Although uptake of TGF- $\beta$ receptors through clathrin-coated pits was shown to link to signaling, uptake through caveolae was implicated in receptor turnover (Di Guglielmo et al. 2003). Thus the pathway of uptake determined a signaling role or degradative fate for the receptor. No overlap was observed between caveolin and an early endosomal marker in this study and so the entire pathwaymediating uptake initiated in caveolae was considered to be quite distinct from that using clathrin-coated pits (Di Guglielmo et al. 2003). This now seems at variance with a number of studies, and in view of the apparent demise of the caveosome as a unique compartment, might need to be reassessed. A number of junctional proteins also use caveolae for entry in response to specific signals such as TNF treatment or epidermal growth factor treatment (Orlichenko et al. 2009; Marchiando et al. 2010).

A second possible role for caveolar endocytosis relates to the need to tightly regulate surface caveolar density ( for other PM functions such as mechanosensation [Parton and Del Pozo 2013]) or to provide a way of transiently regulating plasma membrane composition or properties under specific cellular conditions. During the mammalian cell cycle the density of the caveolae on the surface changes (Boucrot et al. 2011): An imbalance between arrivals and departures 
causes a decrease in caveolae density during metaphase. This is reversed during cytokinesis to return caveolar density to interphase levels. This process might be linked to a role for CAV1 endocytosis in internalization of ordered membrane domains required for Rac1 signaling; in the absence of caveolin cells progress through the cell cycle more rapidly owing to increased membrane order and Rac targeting (Cerezo et al. 2009; Boucrot et al. 2011). This may be partially achieved by loss of the interphase microtubule network as microtuble depolymerization mimics the loss of surface caveolae (Cerezo et al. 2009). This is in agreement with recent work showing a requirement for microtubules in caveola dynamics in a range of tissues (Wickstrom et al. 2010; Malan et al. 2013). Similarly as cells are detached from the substratum there is a net increase in caveolar endocytosis. During mitosis or upon cell detachment, increased PKC $\alpha$-mediated phosphorylation of filamin A allows internalization of caveolae controlling RAC1 targeting to the PM and cell-cycle progression (Muriel et al. 2011).

Caveolae can also act as a major regulator of membrane tension owing to their capacity to passively open up under high mechanical stress, but reform actively thereby being capable of setting membrane tension (Sinha et al. 2011). Because key caveolar coat proteins such as the cavins (including cavin 1/PTRF) are also potentially capable of regulating transcription, and they are released upon application of mechanical stress, this suggests that caveolae could act as a global transducer of this mechanical input (Mayor 2011). For example in muscle cells at high strain, caveolae may buffer membrane tension and mutations that disrupt caveolin, and cavins in muscle have been linked to a number of muscle diseases (Parton and Del Pozo 2013). Regulation of caveolar endocytic dynamics could transiently alter surface caveolae levels and so control the cellular response to tension.

\section{The IL-2R Pathway}

In lymphocytes, cell proliferation is activated by ligand binding to interleukin receptors of various ligand-binding specificities (Gaffen 2001) and is essential for shaping the immune response. Cytokine receptors are endocytosed constitutively, and in ligand-bound states the endocytosis of these receptors follow a CI pathway that is exemplified by the IL-2R pathway described above. These receptors are then sorted toward lysosomes where they are degraded (Hemar et al. 1994, 1995; Subtil et al. 1994). Endocytosis of cytokine receptors via this pathway is also a mechanism to control the signaling cascade and cell proliferation. It has been recently shown that the same mechanism that triggers cell proliferation resulting in PI3P signaling, also via the activation of the PI3P signaling cascade is capable of activating endocytosis via this pathway (Basquin et al. 2013), suggesting the possibility of negative-feedback loops in controlling cell proliferation.

\section{CIE and EGFReceptor Endocytosis}

EGFR endocytosis via clathrin-dependent and -independent mechanisms in the same cells also points toward a very powerful interplay between endocytic mechanisms. Here clathrin-dependent endocytosis regulates the initial signal assembly platform necessary for EGFR signaling (Sigismund et al. 2008), whereas CIE of the EGFR occurs at high doses of EGF (Sigismund et al. 2005). The CIE pathway directs excess EGFR toward a degradative fate by the threshold that is set by the extent of ubiquitination of the substrates of the Ubq-ligase Cbl (Sigismund et al. 2013). The ligase is recruited to the receptor in a sigmoidal fashion related to the extent of ligand-dependent activation of the receptor. This mechanism provides the capacity to exquisitely tune the proliferative drive of a cell by controlling EGFR activity.

\section{CLIC/GEEC and the Arf6-Associated Pathway}

A variety of GPI-APs are internalized by the CG pathway, and therefore it is no surprise that this pathway is used for the function of some of these molecules. An important cargo of GEECs is the folate receptor in which its endocytosis via a CI mechanism specifically aids in accomplishing its capacity to deliver folates to cells (Ritter 
et al. 1995). This must be mediated by the specific colocalization of appropriate folate transporters as well the low $\mathrm{pH}$ of these endosomes to strip the receptor of its folate cargo, captured at the neutral $\mathrm{pH}$ environment of the cell surface (Sabharanjak and Mayor 2004). This pathway could be of vital importance for a number of cargoes where a low concentration bulk ligand is captured at the cell surface and is concentrated at the membrane surface and delivered into the cell via GEECs. Another cargo for a GEEC-like pathway is dysferlin, a muscle repair protein, mutations of which are associated with several myopathies. In cells devoid of CAV1, dysferlin is endocytosed in a dynamin-independent fashion into compartments containing GPI-APs invoking the CG pathway (Hernandez-Deviez et al. 2008).

Considering the constitutive nature and fast kinetics, the CG pathway is a prime candidate for regulating membrane area and consequently tension. It is likely that although clathrinand caveolae-coated pathways respond to large changes in membrane tension, small changes may be buffered by the functioning of the CG pathway. Studies in which PM tension has been modulated have indicated the involvement of a GPI-containing recycling pathway that responds to changes in membrane tension by delivering membrane to the cell surface (Gauthier et al. 2009). Indeed the pleiomorphic nature of the CLICs formed from the cell surface suggests that endocytosis via this pathway could be regulated by membrane tension, and recyling.

The CIE pathway is also involved in regulating cell migration. Both the CG and the Arf6 pathway serve as membrane reservoirs not only of the membrane area required for cell spreading (Gauthier et al. 2009), but a number of key cell-surface proteins involved in membrane attachment (CD44) are also trafficked into the cell via these pathways. This membrane recycling is important for cell adhesion, cell spreading, and cell migration (Song et al. 1998; Santy and Casanova 2001). Brought back to the cell surface are integrins, nutrient transporters, and small $G$ proteins. Directed cell migration is also affected upon inhibition of the CG pathway (Howes et al. 2010a).

\section{FUTURE PERSPECTIVES}

The endocytic activity of caveolae has been a controversial question for many decades. Early models of constitutive uptake were followed by studies suggesting limited endocytosis unless stimulated and even suggestions that caveolae were immobile. More recently a number of different approaches have been used in combination to study caveolae and results from these studies support the idea that caveolae can be constitutive endocytic carriers, but that their endocytic activity can be modulated.

Crucial questions remain about the role and relevance of these pathways in vivo. Studies of transendothelial transport in vivo are a start but we need additional in vivo studies to compare the dynamics of caveolae in different tissues. Overexpression of caveolin or other regulators of the different CIE pathways is clearly a crucial issue and genome-edited cells and tissues (Doyon et al. 2011) will be of immense value in caveolar research. As we learn more of the components that regulate caveolar dynamics but do not play a vital role in caveolar formation we can start to compare cells with active and immobile caveolae. The same applies to key players of the other CIE pathways.

It is clear that there is a dire need for a parts list for all the multiple CIE pathways. It is increasingly likely that this will occur using sophisticated genetic screens that are capable of uncovering perturbations in these pathways. An important question that needs to be addressed is the relationship between the different CIE pathways. Because multiple endocytic pathways exist in a single cell, the cell must have mechanisms to both globally and locally regulate endocytic processes. This implies a considerable amount of molecular wiring that must be dedicated to cross talk between these pathways. Some of this machinery is being discovered serendipitously; overexpression of caveolin caused an inhibition of the CLIC/GEEC pathway, and this was traced to an unappreciated activity of phosphocaveolin to inhibit Cdc42 (Cheng et al. 2010). A systematic monitoring of the correlated expression of the molecular players of these endocytic pathways in different contexts along 
with the endocytic capacity of a few characteristic cargoes will provide valuable information in this context.

In particular, questions about the mechanism and functioning of pathways that operate without both clathrin and dynamin need addressing. Do these pathways represent a spectrum of functionally redundant processes or does each one play a distinct role(s) in particular contexts in a noninterchangeable fashion? Most definitely, an exploration of the roles of these pathways in the development and survival of whole organism models will provide answers to these questions. The development of small molecule inhibitors specific for CIE pathways would clearly help in studies requiring acute regulation of these endocytic processes, and provide a functional dissection of these pathways, and their complex roles in cellular physiology and tissue homeostasis.

\section{REFERENCES \\ ${ }^{*}$ Reference is also in this collection.}

Allaire PD, Seyed Sadr M, Chaineau M, Seyed Sadr E, Konefal S, Fotouhi M, Maret D, Ritter B, Del Maestro RF, McPherson PS. 2013. Interplay between Rab35 and Arf6 controls cargo recycling to coordinate cell adhesion and migration. J Cell Sci 126: 722-731.

Anderson HA, Chen Y, Norkin LC. 1996. Bound simian virus 40 translocates to caveolin-enriched membrane domains, and its entry is inhibited by drugs that selectively disrupt caveolae. Mol Biol Cell 7: 1825-1834.

Babuke T, Tikkanen R. 2007. Dissecting the molecular function of reggie/flotillin proteins. Eur J Cell Biol 86: 525532.

Balasubramanian N, Scott DW, Castle JD, Casanova JE Schwartz MA. 2007. Arf6 and microtubules in adhesiondependent trafficking of lipid rafts. Nat Cell Biol 9: 11.

Barral DC, Garg S, Casalou C, Watts GF, Sandoval JL, Ramalho JS, Hsu VW, Brenner MB. 2012. Arl13b regulates endocytic recycling traffic. Proc Natl Acad Sci 109: 21354-21359.

Basquin C, Malarde V, Mellor P, Anderson DH, Meas-Yedid V, Olivo-Marin JC, Dautry-Varsat A, Sauvonnet N. 2013. The signalling factor PI3K is a specific regulator of the clathrin-independent dynamin-dependent endocytosis of IL-2 receptors. J Cell Sci 126: 1099-1108.

Bastiani M, Liu L, Hill MM, Jedrychowski MP, Nixon SJ, Lo HP, Abankwa D, Luetterforst R, Fernandez-Rojo M, Breen MR, et al. 2009. MURC/Cavin-4 and cavin family members form tissue-specific caveolar complexes. J Cell Biol 185: 1259-1273.

Benesch S, Polo S, Lai FP, Anderson KI, Stradal TE, Wehland J, Rottner K. 2005. N-WASP deficiency impairs EGF in- ternalization and actin assembly at clathrin-coated pits. J Cell Sci 118: 3103-3115.

Bhagatji P, Leventis R, Comeau J, Refaei M, Silvius JR. 2009. Steric and not structure-specific factors dictate the endocytic mechanism of glycosylphosphatidylinositol-anchored proteins. J Cell Biol 186: 615-628.

Bohdanowicz M, Grinstein S. 2013. Role of phospholipids in endocytosis, phagocytosis, and macropinocytosis. Physiol Rev 93: 69-106.

Boucrot E, Howes MT, Kirchhausen T, Parton RG. 2011. Redistribution of caveolae during mitosis. J Cell Sci 124: $1965-1972$

Brown FD, Rozelle AL, Yin HL, Balla T, Donaldson JG. 2001. Phosphatidylinositol 4,5-bisphosphate and Arf6-regulated membrane traffic. J Cell Biol 154: 1007-1017.

* Burd C, Cullen PJ. 2014. Retromer: A master conductor of endosome sorting. Cold Spring Harb Perspect Biol doi: 10.1101/cshperspect.a016774.

Cai B, Katafiasz D, Horejsi V, Naslavsky N. 2011. Pre-sorting endosomal transport of the GPI-anchored protein, CD59, is regulated by EHD1. Traffic 12: 102-120.

Caplan S, Naslavsky N, Hartnell LM, Lodge R, Polishchuk RS, Donaldson JG, Bonifacino JS. 2002. A tubular EHD1containing compartment involved in the recycling of major histocompatibility complex class I molecules to the plasma membrane. EMBO J 21: 2557-2567.

Cerezo A, Guadamillas MC, Goetz JG, Sanchez-Perales S, Klein E, Assoian RK, del Pozo MA. 2009. The absence of caveolin-1 increases proliferation and anchorage-independent growth by a Rac-dependent, Erk-independent mechanism. Mol Cell Biol 29: 5046-5059.

Chadda R, Howes MT, Plowman SJ, Hancock JF, Parton RG, Mayor S. 2007. Cholesterol-sensitive Cdc42 activation regulates actin polymerization for endocytosis via the GEEC pathway. Traffic 8: 702-717.

Chaudhry A, Das SR, Jameel S, George A, Bal V, Mayor S, Rath S. 2007. A two-pronged mechanism for HIV-1 Nefmediated endocytosis of immune costimulatory molecules CD80 and CD86. Cell Host Microbe 1: 37-49.

Cheng ZJ, Singh RD, Holicky EL, Wheatley CL, Marks DL, Pagano RE. 2010. Co-regulation of caveolar and Cdc42-dependent fluid phase endocytosis by phosphocaveolin-1. J Biol Chem 285: 15119-15125.

Conner SD, Schmid SL. 2003. Regulated portals of entry into the cell. Nature 422: 37-44.

* Cossart P, Helenius A. 2014. Endocytosis of viruses and bacteria. Cold Spring Harb Perspect Biol doi: 10.1101/ cshperspect.a016972.

Damke H, Baba T, Warnock DE, Schmid SL. 1994. Induction of mutant dynamin specifically blocks endocytic coated vesicle formation. J Cell Biol 127: 915-934.

Damm EM, Pelkmans L, Kartenbeck J, Mezzacasa A, Kurzchalia T, Helenius A. 2005. Clathrin- and caveolin-1-independent endocytosis: Entry of simian virus 40 into cells devoid of caveolae. J Cell Biol 168: 477-488.

Di Guglielmo GM, Le Roy C, Goodfellow AF, Wrana JL. 2003. Distinct endocytic pathways regulate TGF- $\beta$ receptor signalling and turnover. Nat Cell Biol 5: 410-421.

Doherty GJ, McMahon HT. 2009. Mechanisms of endocytosis. Annu Rev Biochem 78: 857-902. 
Doxsey SJ, Brodsky FM, Blank GS, Helenius A. 1987. Inhibition of endocytosis by anti-clathrin antibodies. Cell 50: $453-463$.

Doyon JB, Zeitler B, Cheng J, Cheng AT, Cherone JM, Santiago Y, Lee AH, Vo TD, Doyon Y, Miller JC, et al. 2011 Rapid and efficient clathrin-mediated endocytosis revealed in genome-edited mammalian cells. Nat Cell Biol 13: 331-337.

Drab M, Verkade P, Elger M, Kasper M, Lohn M, Lauterbach B, Menne J, Lindschau C, Mende F, Luft FC, et al. 2001. Loss of caveolae, vascular dysfunction, and pulmonary defects in caveolin-1 gene-disrupted mice. Science 9: 9.

Egami Y, Fukuda M, Araki N. 2011. Rab35 regulates phagosome formation through recruitment of ACAP2 in macrophages during FcyR-mediated phagocytosis. J Cell Sci 124: 3557-3567.

Eyster CA, Higginson JD, Huebner R, Porat-Shliom N, Weigert R, Wu WW, Shen RF, Donaldson JG. 2009. Discovery of new cargo proteins that enter cells through clathrinindependent endocytosis. Traffic 10: 590-599.

Eyster CA, Cole NB, Petersen S, Viswanathan K, Fruh K, Donaldson JG. 2011. MARCH ubiquitin ligases alter the itinerary of clathrin-independent cargo from recycling to degradation. Mol Biol Cell 22: 3218-3230.

Fivaz M, Vilbois F, Thurnheer S, Pasquali C, Abrami L, Bickel PE, Parton RG, van der Goot FG. 2002. Differential sorting and fate of endocytosed GPI-anchored proteins. EMBO J 21: 3989-4000.

Flannagan RS, Jaumouille V, Grinstein S. 2012. The cell biology of phagocytosis. Annu Rev Pathol 7: 61-98.

Frick M, Bright NA, Riento K, Bray A, Merrified C, Nichols BJ. 2007. Coassembly of flotillins induces formation of membrane microdomains, membrane curvature, and vesicle budding. Curr Biol 17: 1151-1156.

Gaffen SL. 2001. Signaling domains of the interleukin 2 receptor. Cytokine 14: 63-77.

Galletta BJ, Cooper JA. 2009. Actin and endocytosis: Mechanisms and phylogeny. Curr Opin Cell Biol 21: 20-27.

Gauthier NC, Rossier OM, Mathur A, Hone JC, Sheetz MP. 2009. Plasma membrane area increases with spread area by exocytosis of a GPI-anchored protein compartment. Mol Biol Cell 20: 3261-3272.

Geli MI, Riezman H. 1996. Role of type I myosins in receptor-mediated endocytosis in yeast. Science 272: 533-535.

Gesbert F, Sauvonnet N, Dautry-Varsat A. 2004. Clathrinindependent endocytosis and signalling of interleukin 2 receptors IL-2R endocytosis and signalling. Curr Top Microbiol Immunol 286: 119-148.

Glebov OO, Bright NA, Nichols BJ. 2006. Flotillin-1 defines a clathrin-independent endocytic pathway in mammalian cells. Nat Cell Biol 8: 46-54.

Gong Q, Weide M, Huntsman C, Xu Z, Jan LY, Ma D. 2007. Identification and characterization of a new class of trafficking motifs for controlling clathrin-independent internalization and recycling. J Biol Chem 282: 13087-13097.

Gowrishankar K, Ghosh S, Saha SCR, Mayor S, Rao M. 2012. Active remodeling of cortical actin regulates spatiotemporal organization of cell surface molecules. Cell 149: $1353-1367$

Grant BD, Donaldson JG. 2009. Pathways and mechanisms of endocytic recycling. Nat Rev Mol Cell Biol 10: 597-608.
Grant D, Unadkat S, Katzen A, Krishnan KS, Ramaswami M. 1998. Probable mechanisms underlying interallelic complementation and temperature-sensitivity of mutations at the shibire locus of Drosophila melanogaster. Genetics 149: $1019-1030$.

Grassart A, Dujeancourt A, Lazarow PB, Dautry-Varsat A, Sauvonnet N. 2008. Clathrin-independent endocytosis used by the IL-2 receptor is regulated by Racl, Pak1 and Pak2. EMBO Rep 9: 356-362.

Grassart A, Meas-Yedid V, Dufour A, Olivo-Marin JC, Dautry-Varsat A, Sauvonnet N. 2010. Pak1 phosphorylation enhances cortactin-N-WASP interaction in clathrin-caveolin-independent endocytosis. Traffic 11: 1079-1091.

Guha A, Sriram V, Krishnan KS, Mayor S. 2003. Shibire mutations reveal distinct dynamin-independent and -dependent endocytic pathways in primary cultures of Drosophila hemocytes. J Cell Sci 116: 3373-3386.

Gupta GD, Swetha MG, Kumari S, Lakshminarayan R, Dey G, Mayor S. 2009. Analysis of endocytic pathways in Drosophila cells reveals a conserved role for GBF1 in internalization via GEECs. PLoS ONE 4: e6768.

Hansen CG, Nichols BJ. 2010. Exploring the caves: Cavins, caveolins and caveolae. Trends Cell Biol 20: 177-186.

Hansen CG, Howard G, Nichols BJ. 2011. Pacsin 2 is recruited to caveolae and functions in caveolar biogenesis. J Cell Sci 124: 2777-2785.

Hayer A, Stoeber M, Bissig C, Helenius A. 2010a. Biogenesis of caveolae: Stepwise assembly of large caveolin and cavin complexes. Traffic 11: 361-382.

Hayer A, Stoeber M, Ritz D, Engel S, Meyer HH, Helenius A. 2010b. Caveolin-1 is ubiquitinated and targeted to intralumenal vesicles in endolysosomes for degradation. J Cell Biol 191: 615-629.

Hemar A, Lieb M, Subtil A, DiSanto JP, Dautry-Varsat A. 1994. Endocytosis of the $\beta$ chain of interleukin-2 receptor requires neither interleukin-2 nor the $\gamma$ chain. Eur $J$ Immunol 24: 1951-1955.

Hemar A, Subtil A, Lieb M, Morelon E, Hellio R, DautryVarsat A. 1995. Endocytosis of interleukin 2 receptors in human T lymphocytes: Distinct intracellular localization and fate of the receptor $\alpha, \beta$, and $\gamma$ chains. J Cell Biol 129: $55-64$.

Henley JR, Krueger EW, Oswald BJ, McNiven MA. 1998. Dynamin-mediated internalization of caveolae. J Cell Biol 141: 85-99.

* Henne WM, Stenmark H, Emr SD. 2013. Molecular mechanisms of the membrane sculpting ESCRT pathway. Cold Spring Harb Perspect Biol 5: a016766.

Hernandez-Deviez DJ, Howes MT, Laval SH, Bushby K, Hancock JF, Parton RG. 2008. Caveolin regulates endocytosis of the muscle repair protein, dysferlin. J Biol Chem 283: 6476-6488.

Hill MM, Bastiani M, Luetterforst R, Kirkham M, Kirkham A, Nixon SJ, Walser P, Abankwa D, Oorschot VM, Martin S, et al. 2008. PTRF-Cavin, a conserved cytoplasmic protein required for caveola formation and function. Cell 132: $113-124$.

Howes MT, Kirkham M, Riches J, Cortese K, Walser PJ, Simpson F, Hill MM, Jones A, Lundmark R, Lindsay MR, et al. 2010a. Clathrin-independent carriers form a 
S. Mayor et al.

high capacity endocytic sorting system at the leading edge of migrating cells. J Cell Biol 190: 675-691.

Howes MT, Mayor S, Parton RG. 2010b. Molecules, mechanisms, and cellular roles of clathrin-independent endocytosis. Curr Opin Cell Biol 22: 519-527.

Jiang X, Sorkin A. 2003. Epidermal growth factor receptor internalization through clathrin-coated pits requires $\mathrm{Cbl}$ RING finger and proline-rich domains but not receptor polyubiquitylation. Traffic 4: 529-543.

Johannes L, Mayor S. 2010. Induced domain formation in endocytic invagination, lipid sorting, and scission. Cell 142: $507-510$.

* Johannes L, Wunder C, Bassereau. 2014. Bending "on the rocks"-A cocktail of biophysical modules to build endoyctic pathways. Cold Spring Harb Perspect Biol 6: a016741.

Kaksonen M, Sun Y, Drubin DG. 2003. A pathway for association of receptors, adaptors, and actin during endocytic internalization. Cell 115: 475-487.

Kaksonen M, Toret CP, Drubin DG. 2005. A modular design for the clathrin- and actin-mediated endocytosis machinery. Cell 123: 305-320.

Kalia M, Kumari S, Chadda R, Hill MM, Parton RG, Mayor S. 2006. Arf6-independent GPI-anchored protein-enriched early endosomal compartments fuse with sorting endosomes via a Rab5/phosphatidylinositol-3'-kinasedependent machinery. Mol Biol Cell 17: 3689-3704.

* Kirchhausen T, Owen D, Harrison SC, et al. 2014. Molecular Structure, Function and Dynamics of Clathrin-Mediated Membrane Traffic. Cold Spring Harb Perspect Biol doi: 10.1101/cshperspect.a016725.

Kirkham M, Fujita A, Chadda R, Nixon SJ, Kurzchalia TV, Sharma DK, Pagano RE, Hancock JF, Mayor S, Parton RG. 2005. Ultrastructural identification of uncoated caveolin-independent early endocytic vehicles. J Cell Biol 168: $465-476$.

* Klumperman J, Raposo G. 2014. The complex ultrastructure of the endo-lysosome system. Cold Spring Harb Perspect Biol doi: 10.1101/cshperspect.a016857.

Kobayashi H, Fukuda M. 2012. Rab35 regulates Arf6 activity through centaurin- $\beta 2$ (ACAP2) during neurite outgrowth. J Cell Sci 125: 2235-2243.

Kouranti I, Sachse M, Arouche N, Goud B, Echard A. 2006. Rab35 regulates an endocytic recycling pathway essential for the terminal steps of cytokinesis. Curr Biol 16: 17191725.

Kukulski W, Schorb M, Kaksonen M, Briggs JA. 2012. Plasma membrane reshaping during endocytosis is revealed by time-resolved electron tomography. Cell 150: 508-520.

Kumari S, Mayor S. 2008. ARF1 is directly involved in dynamin-independent endocytosis. Nat Cell Biol 10: 30-41.

Kumari S, Borroni V, Chaudhry A, Chanda B, Massol R, Mayor S, Barrantes FJ. 2008. Nicotinic acetylcholine receptor is internalized via a Rac-dependent, dynaminindependent endocytic pathway. J Cell Biol 181: 11791193.

Kumari S, Mg S, Mayor S. 2010. Endocytosis unplugged: Multiple ways to enter the cell. Cell Res 20: 256-275.

Lamaze C, Dujeancourt A, Baba T, Lo CG, Benmerah A, Dautry-Varsat A. 2001. Interleukin 2 receptors and de- tergent-resistant membrane domains define a clathrinindependent endocytic pathway. Mol Cell 7: 661-671.

Liu J, Kaksonen M, Drubin DG, Oster G. 2006. Endocytic vesicle scission by lipid phase boundary forces. Proc Natl Acad Sci 103: 10277-10282.

Ludwig A, Howard G, Mendoza-Topaz C, Deerinck T, Mackey M, Sandin S, Ellisman MH, Nichols BJ. 2013. Molecular composition and ultrastructure of the caveolar coat complex. PLoS Biol 11: e1001640.

Lundmark R, Doherty GJ, Howes MT, Cortese K, Vallis Y, Parton RG, McMahon HT. 2008. The GTPase-activating protein GRAF1 regulates the CLIC/GEEC endocytic pathway. Curr Biol 18: 1802-1808.

Malan D, Elischer A, Hesse M, Wickstrom SA, Fleischmann BK, Bloch W. 2013. Deletion of integrin linked kinase in endothelial cells results in defective RTK signaling caused by caveolin 1 mislocalization. Development 140: 987-995.

Maldonado-Baez L, Cole NB, Kramer H, Donaldson JG. 2013a. Microtubule-dependent endosomal sorting of clathrin-independent cargo by Hook1. J Cell Biol 201: 233-247.

Maldonado-Baez L, Williamson C, Donaldson JG. 2013b. Clathrin-independent endocytosis: A cargo-centric view. Exp Cell Res 319: 2759-2769.

Marchiando AM, Shen L, Graham WV, Weber CR, Schwarz BT, Austin JR 2nd, Raleigh DR, Guan Y, Watson AJ, Montrose $\mathrm{MH}$, et al. 2010. Caveolin-1-dependent occludin endocytosis is required for TNF-induced tight junction regulation in vivo. J Cell Biol 189: 111-126.

Mayor S. 2011. Need tension relief fast? Try caveolae. Cell 144: $323-324$.

Mayor S, Pagano RE. 2007. Pathways of clathrin-independent endocytosis. Nat Rev Mol Cell Biol 8: 603-612.

McIntosh DP, Schnitzer JE. 1999. Caveolae require intact VAMP for targeted transport in vascular endothelium. Am J Physiol 277: H2222-H2232.

McKenzie JE, Raisley B, Zhou X, Naslavsky N, Taguchi T, Caplan S, Sheff D. 2012. Retromer guides STxB and CD8M6PR from early to recycling endosomes, EHD1 guides $\mathrm{STxB}$ from recycling endosome to Golgi. Traffic 13: 1140-1159.

* Merrifield CJ, Kaksonen M. 2014. Endocytic accessory factors and regulation of clathrin-mediated endocytosis. Cold Spring Harb Perspect Biol doi: 10.1101/cshper spect.a016733.

Miaczynska M, Pelkmans L, Zerial M. 2004. Not just a sink: Endosomes in control of signal transduction. Curr Opin Cell Biol 16: 400-406.

Montesano R, Roth J, Robert A, Orci L. 1982. Non-coated membrane invaginations are involved in binding and internalization of cholera and tetanus toxins. Nature 296: 651-653.

Moren B, Shah C, Howes MT, Schieber NL, McMahon HT, Parton RG, Daumke O, Lundmark R. 2012. EHD2 regulates caveolar dynamics via ATP-driven targeting and oligomerization. Mol Biol Cell 23: 1316-1329.

Moya M, Dautry-Varsat A, Goud B, Louvard D, Boquet P. 1985. Inhibition of coated pit formation in Hep2 cells blocks the cytotoxicity of diphtheria toxin but not that of ricin toxin. J Cell Biol 101: 548-559. 
Munn AL, Silveira L, Elgort M, Payne GS. 1991. Viability of clathrin heavy-chain-deficient Saccharomyces cerevisiae is compromised by mutations at numerous loci: Implications for the suppression hypothesis. Mol Cell Biol 11: $3868-3878$.

Munn AL, Stevenson BJ, Geli MI, Riezman H. 1995. end5, end6, and end7: Mutations that cause actin delocalization and block the internalization step of endocytosis in Saccharomyces cerevisiae. Mol Biol Cell 6: 1721-1742.

Muriel O, Echarri A, Hellriegel C, Pavon DM, Beccari L, Del Pozo MA. 2011. Phosphorylated filamin A regulates actin-linked caveolae dynamics. J Cell Sci 124: 2763-2776.

Naslavsky N, Caplan S. 2011. EHD proteins: Key conductors of endocytic transport. Trend Cell Biol 21: 122-131.

Naslavsky N, Weigert R, Donaldson JG. 2003. Convergence of non-clathrin- and clathrin-derived endosomes involves Arf6 inactivation and changes in phosphoinositides. Mol Biol Cell 14: 417-431.

Naslavsky N, Weigert R, Donaldson JG. 2004. Characterization of a nonclathrin endocytic pathway: Membrane cargo and lipid requirements. Mol Biol Cell 15: 3542-3552.

Nishimura Y, Bereczky B, Yoshioka K, Taniguchi S, Itoh K. 2011. A novel role of Rho-kinase in the regulation of ligand-induced phosphorylated EGFR endocytosis via the early/late endocytic pathway in human fibrosarcoma cells. J Mol Histol 42: 427-442.

Ogata T, Ueyama T, Isodono K, Tagawa $\mathrm{M}$, Takehara $\mathrm{N}$, Kawashima T, Harada K, Takahashi T, Shioi T, Matsubara $\mathrm{H}$, et al. 2008. MURC, a muscle-restricted coiled-coil protein that modulates the Rho/ROCK pathway, induces cardiac dysfunction and conduction disturbance. $\mathrm{Mol}$ Cell Biol 28: 3424-3436.

Oh P, McIntosh DP, Schnitzer JE. 1998. Dynamin at the neck of caveolae mediates their budding to form transport vesicles by GTP-driven fission from the plasma membrane of endothelium. J Cell Biol 141: 101-114.

Oh P, Borgstrom P, Witkiewicz H, Li Y, Borgstrom BJ, Chrastina A, Iwata K, Zinn KR, Baldwin R, Testa JE, et al. 2007. Live dynamic imaging of caveolae pumping targeted antibody rapidly and specifically across endothelium in the lung. Nature Biotechnol 25: 327-337.

Oh P, Horner T, Witkiewicz H, Schnitzer JE. 2012. Endothelin induces rapid, dynamin-mediated budding of endothelial caveolae rich in ET-B. J Biol Chem 287: $17353-$ 17362.

Orlichenko L, Weller SG, Cao H, Krueger EW, Awoniyi M, Beznoussenko G, Buccione R, McNiven MA. 2009. Caveolae mediate growth factor-induced disassembly of adherens junctions to support tumor cell dissociation. $\mathrm{Mol}$ Biol Cell 20: 4140-4152.

Otto GP, Nichols BJ. 2011. The roles of flotillin microdomains-Endocytosis and beyond. J Cell Sci 124: $3933-$ 3940.

Park DS, Woodman SE, Schubert W, Cohen AW, Frank PG, Chandra M, Shirani J, Razani B, Tang B, Jelicks LA, et al. 2002. Caveolin-1/3 double-knockout mice are viable, but lack both muscle and non-muscle caveolae, and develop a severe cardiomyopathic phenotype. Am J Pathol 160: 2207-2217.

Parton RG, Del Pozo MA. 2013. Caveolae as plasma membrane sensors, protectors, and organizers. Nat Rev Mol Cell Biol 14: 98-112.
Parton RG, Joggerst B, Simons K. 1994. Regulated internalization of caveolae. J Cell Biol 127: 1199-1215.

Payne GS. 1990. Genetic analysis of clathrin function in yeast. J Membr Biol 116: 93-105.

Pelkmans L, Zerial M. 2005. Kinase-regulated quantal assemblies and kiss-and-run recycling of caveolae. Nature 436: $128-133$.

Pelkmans L, Kartenbeck J, Helenius A. 2001. Caveolar endocytosis of simian virus 40 reveals a new two-step vesicular-transport pathway to the ER. Nat Cell Biol 3: 473483.

Pelkmans L, Burli T, Zerial M, Helenius A. 2004. Caveolinstabilized membrane domains as multifunctional transport and sorting devices in endocytic membrane traffic Cell 118: 767-780.

Piper RC, Lehner PJ. 2011. Endosomal transport via ubiquitination. Trend Cell Biol 21: 647-655.

Powelka AM, Sun J, Li J, Gao M, Shaw LM, Sonnenberg A, Hsu VW. 2004. Stimulation-dependent recycling of integrin $\beta 1$ regulated by ARF6 and Rab11. Traffic 5: 20-36

Puri C. 2009. Loss of myosin VI no insert isoform (NoI) induces a defect in clathrin-mediated endocytosis and leads to caveolar endocytosis of transferrin receptor. $J$ Biol Chem 284: 34998-35014.

Pust S, Dyve AB, Torgersen ML, van Deurs B, Sandvig K. 2010. Interplay between toxin transport and flotillin localization. PLoS ONE 5: e8844.

Radhakrishna H, Donaldson JG. 1997. ADP-ribosylation factor 6 regulates a novel plasma membrane recycling pathway. J Cell Biol 139: 49-61.

Riento K, Frick M, Schafer I, Nichols BJ. 2009. Endocytosis of flotillin-1 and flotillin-2 is regulated by Fyn kinase. $J$ Cell Sci 122: 912-918.

Ritter TE, Fajardo O, Matsue H, Anderson RG, Lacey SW. 1995. Folate receptors targeted to clathrin-coated pits cannot regulate vitamin uptake. Proc Natl Acad Sci 92: 3824-3828.

Rocca A, Lamaze C, Subtil A, Dautry-Varsat A. 2001. Involvement of the ubiquitin/proteasome system in sorting of the interleukin 2 receptor $\beta$ chain to late endocytic compartments. Mol Biol Cell 12: 1293-1301.

Romer W, Berland L, Chambon V, Gaus K, Windschiegl B, Tenza D, Aly MR, Fraisier V, Florent JC, Perrais D, et al 2007. Shiga toxin induces tubular membrane invaginations for its uptake into cells. Nature 450: 670-675.

Romer W, Pontani LL, Sorre B, Rentero C, Berland L, Chambon V, Lamaze C, Bassereau P, Sykes C, Gaus K, et al. 2010. Actin dynamics drive membrane reorganization and scission in clathrin-independent endocytosis. Cell 140: $540-553$.

Saavedra L, Mohamed A, Ma V, Kar S, de Chaves EP. 2007. Internalization of $\beta$-amyloid peptide by primary neurons in the absence of apolipoprotein E. J Biol Chem 282: 35722-35732.

Sabharanjak S, Mayor S. 2004. Folate receptor endocytosis and trafficking. Adv Drug Deliv Rev 56: 1099-1109.

Sabharanjak S, Sharma P, Parton RG, Mayor S. 2002. GPIanchored proteins are delivered to recycling endosomes via a distinct cdc42-regulated, clathrin-independent pinocytic pathway. Dev Cell 2: 411-423. 
S. Mayor et al.

Sandvig K, van Deurs B. 1994. Endocytosis without clathrin. Trend Cell Biol 4: 275-277.

Sandvig K, Torgersen ML, Raa HA, van Deurs B. 2008. Clathrin-independent endocytosis: From nonexisting to an extreme degree of complexity. Histochem Cell Biol 129: $267-276$.

Santy LC, Casanova JE. 2001. Activation of ARF6 by ARNO stimulates epithelial cell migration through downstream activation of both Rac1 and phospholipase D. J Cell Biol 154: 599-610.

Saslowsky DE, Cho JA, Chinnapen H, Massol RH, Chinnapen DJ, Wagner JS, De Luca HE, Kam W, Paw BH, Lencer WI. 2010. Intoxication of zebrafish and mammalian cells by cholera toxin depends on the flotillin/reggie proteins but not Derlin-1 or -2. J Clin Invest 120: 4399 4409.

Sato M, Sato K, Liou W, Pant S, Harada A, Grant BD. 2008. Regulation of endocytic recycling by C. elegans Rab35 and its regulator RME-4, a coated-pit protein. $E M B O J$ 27: 1183-1196.

Schnitzer JE, Liu J, Oh P. 1995. Endothelial caveolae have the molecular transport machinery for vesicle budding, docking, and fusion including VAMP, NSF, SNAP, annexins, and GTPases. J Biol Chem 270: 14399-14404.

Senju Y, Itoh Y, Takano K, Hamada S, Suetsugu S. 2011. Essential role of PACSIN2/syndapin-II in caveolae membrane sculpting. J Cell Sci 124: 2032-2040.

Sharma P, Varma R, Sarasij RC, Ira, Gousset K, Krishnamoorthy G, Rao M, Mayor S. 2004. Nanoscale organization of multiple GPI-anchored proteins in living cell membranes. Cell 116: 577-589.

Shi A, Liu O, Koenig S, Banerjee R, Chen CC, Eimer S, Grant BD. 2012. RAB-10-GTPase-mediated regulation of endosomal phosphatidylinositol-4,5-bisphosphate. Proc Natl Acad Sci 109: E2306-E2315.

Sigismund S, Woelk T, Puri C, Maspero E, Tacchetti C, Transidico P, Di Fiore PP, Polo S. 2005. Clathrin-independent endocytosis of ubiquitinated cargos. Proc Natl Acad Sci 102: $2760-2765$.

Sigismund S, Argenzio E, Tosoni D, Cavallaro E, Polo S, Di Fiore PP. 2008. Clathrin-mediated internalization is essential for sustained EGFR signaling but dispensable for degradation. Dev Cell 15: 209-219.

Sigismund S, Algisi V, Nappo G, Conte A, Pascolutti R, Cuomo A, Bonaldi T, Argenzio E, Verhoef LG, Maspero E, et al. 2013. Threshold-controlled ubiquitination of the EGFR directs receptor fate. EMBO J 32: 2140-2157.

Simionescu M, Gafencu A, Antohe F. 2002. Transcytosis of plasma macromolecules in endothelial cells: A cell biological survey. Microsc Res Tech 57: 269-288.

Sinha B, Koster D, Ruez R, Gonnord P, Bastiani M, Abankwa D, Stan RV, Butler-Browne G, Vedie B, Johannes L, et al. 2011. Cells respond to mechanical stress by rapid disassembly of caveolae. Cell 144: 402-413.

Song J, Khachikian Z, Radhakrishna H, Donaldson JG. 1998. Localization of endogenous ARF6 to sites of cortical actin rearrangement and involvement of ARF6 in cell spreading. J Cell Sci 111: 2257-2267.

Spoden G, Freitag K, Husmann M, Boller K, Sapp M, Lambert C, Florin L. 2008. Clathrin- and caveolin-independent entry of human papillomavirus type 16-Involve- ment of tetraspanin-enriched microdomains (TEMs). PLoS ONE 3: e3313.

Stachowiak JC, Schmid EM, Ryan CJ, Ann HS, Sasaki DY, Sherman MB, Geissler PL, Fletcher DA, Hayden CC. 2012. Membrane bending by protein-protein crowding. Nat Cell Biol 14: 944-949.

Stang E, Kartenbeck J, Parton RG. 1997. Major histocompatibility complex class I molecules mediate association of SV40 with caveolae. Mol Biol Cell 8: 47-57.

Stoeber M, Stoeck IK, Hanni C, Bleck CK, Balistreri G, Helenius A. 2012. Oligomers of the ATPase EHD2 confine caveolae to the plasma membrane through association with actin. EMBO J 31: 2350-2364.

Subtil A, Hemar A, Dautry-Varsat A. 1994. Rapid endocytosis of interleukin 2 receptors when clathrin-coated pit endocytosis is inhibited. J Cell Sci 107: 3461-3468.

Sverdlov M, Shinin V, Place AT, Castellon M, Minshall RD. 2009. Filamin A regulates caveolae internalization and trafficking in endothelial cells. Mol Biol Cell 20: 45314540.

Tagawa M, Ueyama T, Ogata T, Takehara N, Nakajima N, Isodono K, Asada S, Takahashi T, Matsubara $\mathrm{H}$, Oh $\mathrm{H}$. 2008. MURC, a muscle-restricted coiled-coil protein, is involved in the regulation of skeletal myogenesis. $\mathrm{Am}$ J Physiol Cell Physiol 295: C490-C498.

Tan PK, Davis NG, Sprague GF, Payne GS. 1993. Clathrin facilitates the internalization of seven transmembrane segment receptors for mating pheromones in yeast. $J$ Cell Biol 123: 1707-1716.

Thomsen P, Roepstorff K, Stahlhut M, van Deurs B. 2002. Caveolae are highly immobile plasma membrane microdomains, which are not involved in constitutive endocytic trafficking. Mol Biol Cell 13: 238-250.

Timpson P, Lynch DK, Schramek D, Walker F, Daly RJ. 2005. Cortactin overexpression inhibits ligand-induced downregulation of the epidermal growth factor receptor. Cancer Res 65: 3273-3280.

Toret CP, Drubin DG. 2006. The budding yeast endocytic pathway. J Cell Sci 119: 4585-4587.

Tran D, Carpentier JL, Sawano F, Gorden P, Orci L. 1987. Ligands internalized through coated or noncoated invaginations follow a common intracellular pathway. Proc Natl Acad Sci 84: 7957-7961.

Way M, Parton RG. 1995. M-caveolin, a muscle-specific caveolin-related protein. FEBS Lett 376: 108-112.

Weigert R, Yeung AC, Li J, Donaldson JG. 2004. Rab22a regulates the recycling of membrane proteins internalized independently of clathrin. Mol Biol Cell 15: 3758-3770.

Weinberg J, Drubin DG. 2012. Clathrin-mediated endocytosis in budding yeast. Trend Cell Biol 22: 1-13.

Wickstrom SA, Lange A, Hess MW, Polleux J, Spatz JP, Kruger M, Pfaller K, Lambacher A, Bloch W, Mann M, et al. 2010. Integrin-linked kinase controls microtubule dynamics required for plasma membrane targeting of caveolae. Dev Cell 19: 574-588.

Zimmermann P, Tomatis D, Rosas M, Grootjans J, Leenaerts I, Degeest G, Reekmans G, Coomans C, David G. 2001. Characterization of syntenin, a syndecan-binding PDZ protein, as a component of cell adhesion sites and microfilaments. Mol Biol Cell 12: 339-350. 


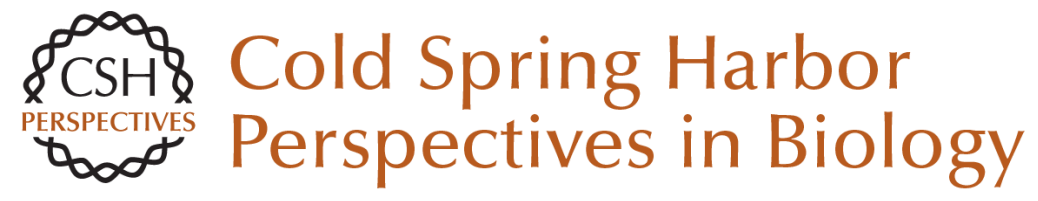

\section{Clathrin-Independent Pathways of Endocytosis}

Satyajit Mayor, Robert G. Parton and Julie G. Donaldson

Cold Spring Harb Perspect Biol 2014; doi: 10.1101/cshperspect.a016758

Subject Collection Endocytosis

Endocytosis: Past, Present, and Future Sandra L. Schmid, Alexander Sorkin and Marino Zerial

Rab Proteins and the Compartmentalization of the Endosomal System

Angela Wandinger-Ness and Marino Zerial

Cargo Sorting in the Endocytic Pathway: A Key Regulator of Cell Polarity and Tissue Dynamics Suzanne Eaton and Fernando Martin-Belmonte

Unconventional Functions for Clathrin, ESCRTs, and Other Endocytic Regulators in the

Cytoskeleton, Cell Cycle, Nucleus, and Beyond:

Links to Human Disease

Frances M. Brodsky, R. Thomas Sosa, Joel A. Ybe, et al.

Endocytosis of Viruses and Bacteria Pascale Cossart and Ari Helenius

Lysosomal Adaptation: How the Lysosome

Responds to External Cues Carmine Settembre and Andrea Ballabio

Reciprocal Regulation of Endocytosis and Metabolism

Costin N. Antonescu, Timothy E. McGraw and Amira Klip

Endocytosis and Autophagy: Exploitation or Cooperation?

Sharon A. Tooze, Adi Abada and Zvulun Elazar
Imaging and Modeling the Dynamics of

Clathrin-Mediated Endocytosis

Marcel Mettlen and Gaudenz Danuser

Endocytic Accessory Factors and Regulation of

Clathrin-Mediated Endocytosis

Christien J. Merrifield and Marko Kaksonen

The Complex Ultrastructure of the Endolysosomal

System Judith Klumperman and Graça Raposo

The Biogenesis of Lysosomes and

Lysosome-Related Organelles J. Paul Luzio, Yvonne Hackmann, Nele M.G. Dieckmann, et al.

Endocytosis, Signaling, and Beyond Pier Paolo Di Fiore and Mark von Zastrow

Clathrin-Independent Pathways of Endocytosis Satyajit Mayor, Robert G. Parton and Julie G. Donaldson

The Role of Endocytosis during Morphogenetic Signaling Marcos Gonzalez-Gaitan and Frank Jülicher

Role of Endosomes and Lysosomes in Human Disease

Frederick R. Maxfield

For additional articles in this collection, see http://cshperspectives.cshlp.org/cgi/collection/

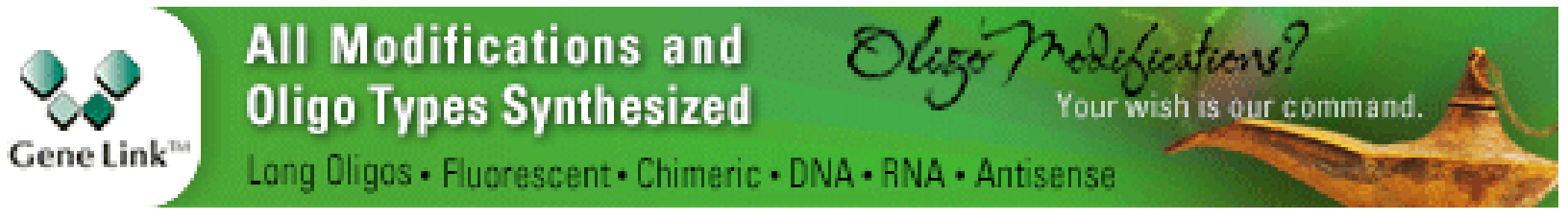


For additional articles in this collection, see http://cshperspectives.cshlp.org/cgi/collection/

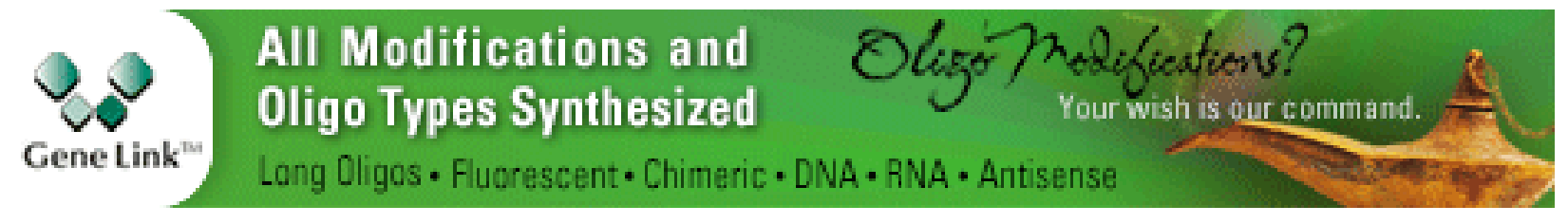

Copyright @ 2014 Cold Spring Harbor Laboratory Press; all rights reserved 